\title{
Characterization of genetic alteration patterns in human esophageal squamous cell carcinoma using selected microsatellite markers spanning multiple loci
}

\author{
YUYANG CHRISTINE CAI ${ }^{1 *}$, CHI K. SO ${ }^{1 *}$, ALEX YAN NIE ${ }^{1,4}$, YUNLONG SONG $^{1}$, GUANG-YU YANG $^{1,3,5}$, \\ LI-DONG WANG ${ }^{2}$, XIN ZHAO ${ }^{1}$, TERRI GOSS KINZY ${ }^{3}$ and CHUNG S. YANG ${ }^{1}$ \\ ${ }^{1}$ Department of Chemical Biology, Ernest Mario School of Pharmacy, Rutgers, The State University of New Jersey, \\ 164 Frelinghuysen Road, Piscataway, NJ 08854-8020 USA; ${ }^{2}$ Laboratory for Cancer Research, Zhengzhou University, \\ Zhengzhou, Henan 457500, P.R. China; ${ }^{3}$ Department of Molecular Genetics and Microbiology, University of Medicine \\ and Dentistry of New Jersey, Robert Wood Johnson Medical School, Piscataway, NJ 08854, USA
}

Received June 8, 2006; Accepted July 28, 2006

\begin{abstract}
In order to identify representative genetic alterations in esophageal squamous cell carcinomas (ESCC) and useful markers for future early detection, 34 ESCC samples with neighboring normal epithelia and 30 esophageal biopsy samples from Linzhou, P.R. China, were studied. Of the 38 microsatellite markers selected, half were linked with tumor suppressors. More than $40 \%$ of the tumor samples showed loss of heterozygosity $(\mathrm{LOH})$ in at least one of the eight markers, D3S1067 and D3S1561 (both linked to hMLH1 locus), FABP2, D4S1613, D9S171 (p14 ARF, p15 INK4b,$p 16^{\text {INK4a } l o c i), ~ R b 1 ~}$ (intron), p53-2 (intron), and NM23-H1. Most of the 38 microsatellite markers did not display microsatellite instability (MSI) in more than $30 \%$ of the tumor samples, except D9S942
\end{abstract}

Correspondence to: Dr Chung S. Yang, Department of Chemical Biology, Ernest Mario School of Pharmacy, Rutgers, The State University of New Jersey, 164 Frelinghuysen Road, Piscataway, NJ 08854-8020, USA

E-mail: csyang@rci.rutgers.edu

Present addresses: ${ }^{4}$ Johnson \& Johnson Pharmaceutical Research \& Development L.L.C. 1000 US Route 202, Raritan, NJ 08869, USA; ${ }^{5}$ Northwestern University, Department of Pathology, Ward 6-118, Feinberg School of Medicine, 303 East Chicago Ave., Chicago, IL 606011, USA

${ }^{*}$ Contributed equally

Abbreviations: ESCC, esophageal squamous cell carcinomas; hMLH1, human Mut L homologue-1; hMSH2, human Mut S homologue-2; LOH, loss of heterozygosity; MSI, microsatellite instability; $\mathrm{BCH}$, basal cell hyperplasia; DYS, dysplasia; CDK, cyclin-dependent kinase; SNP, single nucleotide polymorphisms

Key words: LOH, MSI, genetic instability, human esophageal cancer $\left(p 14^{A R F}, p 15^{I N K 4 b}, p 16^{I N K 4 a}\right.$ loci) and Bat26, which showed frequency at 32 and $41 \%$, respectively. Of all the ESCC samples examined, 20 samples exhibited $\mathrm{LOH}$ in $25 \%$ or more of the informative markers. Three samples displayed MSI in more than $30 \%$ of the markers, indicating that MSI might be an important event in these subset ESCC cases. Statistically significant correlations were found between $\mathrm{LOH}$ of the $h M L H 1$ locus and the general LOH status of the sample, and between the LOH of the hMLH1 locus and p53 mutations. In addition, correlation was found between MSI in D3S1067/D3S1561 and the general MSI status in the samples. However, MSI in the introns of $h M L H 1$ and $h M S H 2$ were not correlated with the general MSI status of the tumors. LOH analysis was also performed in 30 esophageal biopsy samples containing precancerous lesions with matching blood samples using nine microsatellite markers selected from the above studies. $\mathrm{LOH}$ frequence ranged from 0 to $33 \%$ in informative cases, mostly in the 9p21 and p53 gene regions, suggesting these regions are possible targets of genomic instability in early stage ESCC carcinogenesis. The results demonstrate the degree of genetic alterations at different loci of the chromosomes. Some of the microsatellite markers may be useful for the early detection of ESCC.

\section{Introduction}

Esophageal cancer is the sixth most common cancer worldwide (1). Due to difficulties in early diagnosis and poor efficacy of treatment of ESCC, the 5-year survival rate is below $13 \%$. Epidemiological studies have identified tobacco, alcohol, micronutrient deficiencies, nitrosamines, mycotoxins, physical injury, and chronic inflammation as major risk factors in $\operatorname{ESCC}(2,3)$.

Genetic alterations are important molecular changes in the progression of ESCC. Our laboratory has been studying genetic alterations in ESCC samples from Linzhou (formally Linxian), a well-recognized high ESCC incidence region in the Henan Province, in Northern China (4). In previous studies, frequent alterations in the $p 53$ and $R b$ tumor suppressor path- 
ways have been identified in these ESCC samples (5-7). Our data showed that mutation of the $p 53$ gene and accumulation of p53 protein were early events observable in epithelia with basal cell hyperplasia and dysplasia $(4,5)$. Samples were frequently found with loss of heterozygosity $(\mathrm{LOH})$ of the $R b$ gene and contained reduced level of $\mathrm{Rb}$ protein expression (6). We also analyzed genetic alterations for three co-located CDK inhibitors, the $p 14^{A R F}$, p15 $15^{I N K 4 b}$, and $p 16^{I N K 4 a}$ genes, which are known to play important roles in the p53 and Rb tumor suppression pathways. We detected aberrant hypermethylation of $p 16^{I N K 4 a}$ promoter region and decrease or loss of $p 16^{I N K 4}$ gene expression. The $p 14^{A R F}$ and $p 15^{I N K 4 b}$ genes were also inactivated by homozygous deletion and hypermethylation (8). Based on these results, we suggested that the aberration of both the $\mathrm{Rb}$ and $\mathrm{p} 53$ tumor suppressor pathways are needed in esophageal carcinogenesis (7). We also observed the hypermethylation and inactivation of HLA class I gene, $h M L H 1$, retinoic acid receptor beta (RARß), $O^{6}$-methylguanine-DNA methyltransferase (MGMT), and other genes in resected and biopsy esophageal samples with different lesions. MGMT, $R A R \beta, h M L H 1$, and $p 16^{I N K 4 a}$ hypermethylation are likely to occur at the early stage of ESCC carcinogenesis (5-7,9-13). Using laser-microdissected DNA samples, others have detected genetic alterations within various chromosomal loci $(14,15)$. LOH were detected on chromosomes $3 p, 4 p, 9 q$ and $13 q$, which may be involved in early carcinogenesis of ESCC. In addition, $\mathrm{LOH}$ within chromosomes $8 \mathrm{p}, 9 \mathrm{p}, 11 \mathrm{p}$, and $17 \mathrm{p}$ were also observed. These chromosomal changes may be associated with late stage of the disease. SNP genotyping for linkage analysis has also been used to identify new genes that might be involved in the development of ESCC (14-16). In order to identify molecular markers for early cancer detection, we analyzed the alteration of microsatellite markers for selected tumor suppressor genes.

Genetic alterations such as microsatellite instability (MSI) and $\mathrm{LOH}$ are likely to occur at the early stage of tumorigenesis in head and neck squamous cell carcinoma (17). Although the frequency of MSI or LOH for an individual microsatellite marker may be low at the early stage, the combination of a group of markers may serve as a highly informative biomarker for the early diagnosis of cancer. From our previous studies $(7,8)$, the genetic progression model for head and neck squamous cell carcinoma (17), and other information from the literature (17-23), we selected 38 microsatellite markers on chromosomal arms 2p, 3p, 4q, 5q, 6p, 8p, 8q, 9q, 11p, $11 \mathrm{q}, 13 \mathrm{q}, 14 \mathrm{q}, 17 \mathrm{p}, 17 \mathrm{q}, 18 \mathrm{q}$, and $19 \mathrm{q}$ to detect genetic alterations. Half of these markers are linked with tumor suppressors that might have an important role in ESCC development. Based on the LOH/MSI results from ESCC samples, we further analyzed genetic alterations in biopsy samples containing precancerous lesions with the goal of developing biomarkers for the early detection of ESCC.

\section{Materials and methods}

Esophageal tissue specimens and DNA extraction. Resected human ESCC samples together with neighboring normal esophageal epithelia were obtained within $1 \mathrm{~h}$ after surgery from 34 patients in Linzhou (formerly Linxian) of Henan, P.R. China. The tissues were frozen in liquid nitrogen and stored at $-80^{\circ} \mathrm{C}$ until use. Part of the tumor tissue and adjacent normal epithelia tissue was cryosected at $-20^{\circ} \mathrm{C}$ into $14-\mu \mathrm{m}$ sections for haematoxylin and eosin (H\&E) staining or $20-\mu \mathrm{m}$ sections for DNA preparation, and kept at $-80^{\circ} \mathrm{C}$ until use. The tumors and normal epithelia in the frozen sections were determined histopathologically with $\mathrm{H} \& \mathrm{E}$ stained slides in the same region. The normal cell contamination in tumor cells in the samples used was estimated to be less than $30 \%$. Biopsy samples were collected from the same population with matching blood samples from the same individual. Thirty biopsy samples containing $\mathrm{BCH}$ or DYS lesions as diagnosed histopathologically were cryosected at $-20^{\circ} \mathrm{C}$ into $20-\mu \mathrm{m}$ sections. The QiaAmp Tissue Kit (Qiagen, Cat. No. 29304) was used to extract and purify DNA from tissue and biopsy samples, and Qiagen Blood Kit was used for matched blood samples.

Primers and polymerase chain reaction (PCR). The forward primer of each pair was labeled at the 5'-end with fluorescent dyes HEX, 6-FAM, or TET (PE Biosystems, Foster City, $\mathrm{CA}$ ). The primers were synthesized, labeled, and purified by Integrated DNA Technologies, Inc. (Coralville, IA). The target DNA sequences from paired tumor and normal tissues were amplified side by side in a $20-\mu 1$ PCR reaction containing $1 \mathrm{X}$ GeneAmp PCR Buffer II, 20 pmoles of each primer, $1 \mathrm{U}$ AmpliTaq Gold DNA Polymerase, $1.5 \mathrm{mM} \mathrm{MgCl}_{2}, 50 \mu \mathrm{M}$ each of dATP, dCTP, dGTP, dTTP, and DNA. All of the amplifications were carried out in the GeneAmp PCR System 9700. The annealing temperature and the cycle number were optimized for each pair of primers. The PCR system and reagents used were from PE Applied Biosystems.

Polyacrylamide gel electrophoresis. PCR products were analyzed on 5\% polyacrylamide denaturing gels in a Model 377 automated fluorescent DNA sequencer, which is a four-color detection system. Thirty-four individual PCR products of a sample were pooled into 5 groups based on different sizes or colors. The intensity ratio of the dyes 6-FAM:TET:HEX was $1: 1: 2$. The PCR product mix $(1.5-2.0 \mu \mathrm{l})$ was combined with $2.4 \mu 1$ deionized formamide, $0.8 \mu 1$ TRAMA-500 labeled fluorescent size standard marker (PE Biosystems), and $0.8 \mu 1$ of loading buffer. Following denaturation for $5 \mathrm{~min}$ at $95^{\circ} \mathrm{C}$, $0.7 \mu 1$ was loaded into each well on the pre-warmed $5 \%$ polyacrylamide $6 \mathrm{M}$ urea gel. The tumor and normal samples from the same subject were loaded side by side. The gel was run for $2 \mathrm{~h}$ at $3000 \mathrm{~V}$ and $51^{\circ} \mathrm{C}$. While the samples were undergoing electrophoresis, the fluorescence detected in the laser scanning region was collected, stored by the GeneScan Software, and analyzed by GenoTyper Software. Two independent PCR analyses with the fluorescence DNA sequencer were performed. The DNA sequencer, reagents, and software were from PE Applied Biosystems.

Calculation of allele ratios and $\mathrm{LOH}$ assessment. The peaks produced by the normal DNA samples were used to determine whether the samples were non-informative (one peak or one peak stutter) or informative (two peaks or two peak stutters). The highest peak of the stutter was used to represent the peak size and height of the allele. The peak ratio of alleles was calculated for each normal/tumor pair of each marker as 


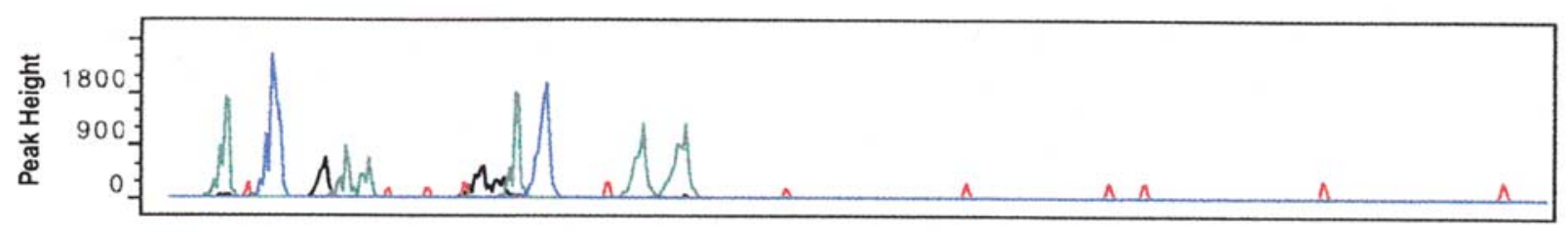

Peak Size (BP) $80 \quad 100 \quad 120 \quad 140 \quad 160 \quad 180 \quad 200 \quad 220 \quad 240 \quad 260 \quad 280 \quad 300 \quad 320 \quad 340 \quad 360 \quad 380 \quad 400 \quad 420 \quad 440$

(A)

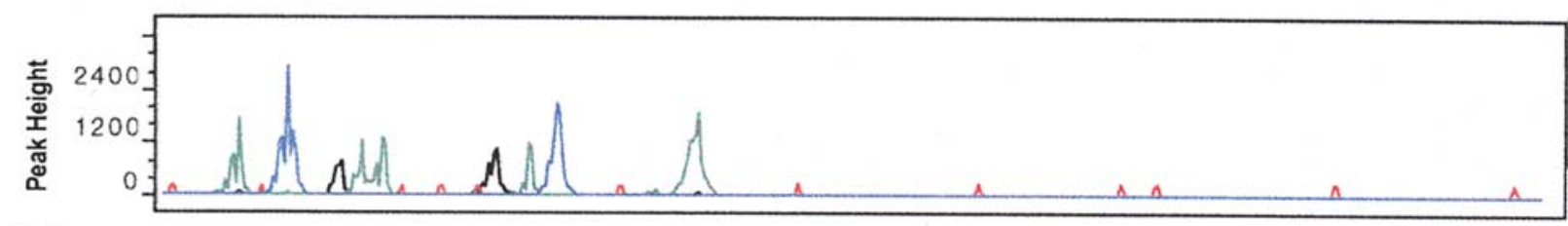

Peak Size (BP) $80 \quad 100 \quad 120 \quad 140 \quad 160 \quad 180 \quad 200 \quad 220 \quad 240 \quad 260 \quad 280 \quad 300 \quad 320 \quad 340 \quad 360 \quad 380 \quad 400 \quad 420 \quad 440$

(B)

Figure 1. Diagram of MSI and LOH analyses from the fluorescence DNA sequencer. The red peaks are size standards. The green peaks are TET-labeled products representing D3S1067, D8S273, D9S736, and D13S170 in size order (from small to large). The blue peaks are FAM-labeled representing D8S257 and D14S81 in size order. The black peaks are HEX-labeled representing D3S1038 and IMG412 in size order. Information on the peak sizes and heights are summarized in Table I. A, Diagram of normal epithelia from subject \#27. B, Diagram of the tumor sample from the same subject.

$\mathrm{N} 1 * \mathrm{~T} 2 /(\mathrm{N} 2 * \mathrm{~T} 1)$. A ratio of $\leq 0.5$ or $\geq 2$ was regarded as an indicator of $\mathrm{LOH}$; a ratio between 0.67 and 1.5 was regarded as no change or normal status. A ratio in the range of $0.5-0.67$ or 1.5-2 was classified as 'decreased allelic ratio', indicating that $\mathrm{LOH}$ could not be determined.

MSI assessment. MSI was determined by the shift of 2 bp or more of the peaks or new peaks in the tumor sample compared to the corresponding normal sample. For single nucleotide repeat, one base pair shift was considered MSI (24).

\section{Results}

LOH and MSI frequencies of the markers. Fifty-eight microsatellite markers were used in our preliminary study, 38 of which were selected based on heterozygosity, cytogenetic distribution, and amplification efficiency. A total of 34 pairs of normal and ESCC samples were analyzed initially for LOH with the markers. An example is shown in Fig. 1. Eight markers were separated in one lane of the gel and identified by size and color. The results of all 8 markers of this sample, shown in Fig. 1, are summarized in Table I. A distribution analysis was performed to help define criteria to determine $\mathrm{LOH}$. The allelic ratio of 2, which is widely used (24-26), was chosen as the cut-off point. Because of the possible contamination by non-tumor cells or presence of subpopulations of heterozygous malignant cells from different clones within the same tumor, we consider the range of 1.52.0 (or $0.5-0.67$ ) as 'decreased allelic ratio', and it was excluded from the determination of $\mathrm{LOH}$. We also considered all the cases showing MSI as non-informative in the LOH study (24). According to these criteria, $\mathrm{LOH}$ in 2 markers and MSI in 1 marker were observed among the eight markers for this sample (Table I).

The LOH and MSI frequencies of the microsatellite markers in 34 pairs of samples are summarized in Table II. LOH occurred at high frequencies with an average of $30.8 \%$ in the informative cases. More than $40 \%$ of the samples showed $\mathrm{LOH}$ in at least one of the eight markers, D3S1067 and D3S1561 (linked to $h M L H 1$ ), FABP2, D4S1613, D9S171 (p14 ${ }^{A R F}, p 15^{I N K 4 b}, p 16^{I N K 4 a}$ loci), RB1 (intron), p53 (intron), and NM23-H. Marker D8S257, however, showed no LOH in any samples, although its heterozygosity was higher than 0.5 . Like LOH, the MSI of the 38 markers also showed great variation (Table II). Bat26 and D9S942 displayed high frequencies of MSI, at 41 and 32\%, respectively; 19 markers had MSI in less than $10 \%$ of the samples, including two markers without any detectable instability.

LOH and MSI frequencies in the ESCC samples. Twenty of the 34 ESCC samples exhibited LOH in at least $25 \%$ of the informative markers (Table III): 6 samples were diagnosed as poorly differentiated ESCC; 3 were moderately differentiated; 11 were well differentiated.

An average of 4.4 out of the 38 markers displayed MSI in each ESCC sample. Three samples displayed MSI at more than $30 \%$ of the 38 markers, among which two were well differentiated and one was poorly differentiated. Based on the criteria proposed by the National Workshop on Colorectal Cancer (27), all three were MSI-H. Five samples showed MSI in 18-30\% of the markers, all of which were well differentiated ESCC. No MSI was observed in 6 samples, of which 3 had LOH higher than $30 \%$.

hMLH1 and hMSH2. Three microsatellite markers (D3S1611, D3S1067, and D3S1561) were linked to the hMLH1 gene. D3S1611, located within the intron sequence of the gene, displayed MSI in 7 out of $34(20.6 \%)$ tumor samples and $\mathrm{LOH}$ in 7 out of 18 (38.9\%) informative cases. D3S1561, closely linked to $h M L H 1$, showed MSI in only 3 tumor samples $(8.8 \%)$. However, this marker contained $\mathrm{LOH}$ in 9 out of 20 $(45 \%)$ informative cases. There were 7 tumor samples $(20.6 \%)$ 
Table I. Results of allelic analyses of sample no. 27 shown in Fig. 1.

\begin{tabular}{|c|c|c|c|c|c|c|c|}
\hline Sample & Marker & $\begin{array}{l}\text { Size of } \\
\text { allele } 1\end{array}$ & $\begin{array}{l}\text { Height of } \\
\text { allele } 1\end{array}$ & $\begin{array}{l}\text { Size of } \\
\text { allele } 2\end{array}$ & $\begin{array}{l}\text { Height of } \\
\text { allele } 2\end{array}$ & $\begin{array}{c}\text { Allelic } \\
\text { ratio }^{\mathrm{a}}\end{array}$ & $\mathrm{LOH} / \mathrm{MSI}$ \\
\hline $27 N$ & D8S273 & 127.32 & 878 & 133.58 & 716 & & \\
\hline $27 \mathrm{~T}$ & D8S273 & 127.88 & 1280 & 133.89 & 1376 & 0.759 & Normal \\
\hline $27 N$ & D8S257 & 106.8 & 2478 & 0 & 0 & & \\
\hline $27 \mathrm{~T}$ & D8S257 & 107.24 & 2978 & 0 & 0 & N/A & NI \\
\hline $27 N$ & D9S736 & 174.57 & 1853 & 0 & 0 & & \\
\hline $27 \mathrm{~T}$ & D9S736 & 174.46 & 1180 & 0 & 0 & N/A & NI \\
\hline $27 \mathrm{~N}$ & D14S81 & 182.97 & 1971 & 0 & 0 & & \\
\hline $27 \mathrm{~T}$ & D14S81 & 181.95 & 2134 & 0 & 0 & N/A & MSI \\
\hline $27 N$ & IMG412 & 165.11 & 578 & 170.81 & 358 & & \\
\hline $27 \mathrm{~T}$ & IMG412 & 165.11 & 1047 & 0 & 0 & 0 & $\mathrm{LOH}$ \\
\hline $27 N$ & D13S170 & 209.95 & 1338 & 221.84 & 1282 & & \\
\hline $27 \mathrm{~T}$ & $\mathrm{D} 13 \mathrm{~S} 170$ & 0 & 0 & 221.86 & 1912 & Infinity & $\mathrm{LOH}$ \\
\hline $27 N$ & D3S1067 & 94.11 & 1798 & 0 & 0 & & \\
\hline $27 \mathrm{~T}$ & D3S1067 & 93.82 & 1778 & 0 & 0 & N/A & NI \\
\hline $27 N$ & D3S1038 & 121.59 & 696 & 0 & 0 & & \\
\hline $27 \mathrm{~T}$ & D3S1038 & 122.15 & 802 & 0 & 0 & N/A & NI \\
\hline
\end{tabular}

${ }^{\text {a Allelic ratio }}=\mathrm{N} 1 * \mathrm{~T} 2 /(\mathrm{N} 2 * \mathrm{~T} 1)$. $\mathrm{LOH}$, allelic ratio $\geq 2$ or $\leq 0.5$; Decreased allelic ratio, $1.5<$ allelic ratio $<2$ or $0.5<$ allelic ratio $<0.67$; Normal, $0.67 \leq$ allelic ratio $\leq 1.5$. NI, non-informative; N/A, not available.

with MSI and 12 out of $22(54.5 \%)$ informative cases exhibited LOH on D31067, which is also in this locus. Two tumor samples (nos. 25 and 28) showed MSI in all three markers. These 2 samples also displayed a high incidence of MSI (24 and 58\%) among the 38 markers used in this study. One tumor sample (no. 6) had MSI in D3S1067 and D3S1561, but not in D3S1611. This sample also displayed a high ratio of MSI (42\%) among the 38 markers. Among the 31 samples, in which at least one of the three markers was informative, 6 cases did not display either LOH or MSI among the three markers, and none of these cases had $\mathrm{LOH}$ at frequency over $20 \%$ or MSI frequency over $10 \%$ for the 38 markers.

Microsatellite marker, Bat26, which is on locus 2p16, was used to assess chromosomal stability within the hMSH2 gene. MSI was observed in 14 of the 34 samples (42\%). However, no LOH was observed with Bat26.

Correlation between the status of the microsatellite markers linked to hMLH1/hMSH2 and those of the remaining 34 markers. For the 34 markers not linked to the $h M L H 1$ or $h M S H 2$, we also evaluated the overall $\mathrm{LOH}$ rate in these samples. The background $\mathrm{LOH}$ rate is generally less than $22 \%$ (28-30). In our analysis, samples with an overall LOH rate above $25 \%$ were considered $\mathrm{LOH}$ positive. Using this criterion, we identified 16 out of 34 ESCC samples to be
LOH positive. To study the relationship between the general $\mathrm{LOH}$ level of a sample and the status of DNA mismatch repair gene $h M L H 1$, D3S1611 was regarded as the primary indicator, since it is located within the intron of the gene. When D3S1611 was non-informative, D3S1561 was used instead; and if both D3S1611 and D3S1561 were noninformative, D3S1067 was used. Our data showed that the LOH status of the $h M L H 1$ locus was significantly correlated with the LOH level of the sample as indicated by the 34 markers (the Fisher's exact P-value was 0.0005, Table IV).

As shown in Table III, most of the samples contained MSI in less than $18 \%$ of the 34 markers. Therefore, samples with an overall MSI rate above the background $18 \%$ are considered MSI positive. Using this criterion, we identified 8 out of 34 ESCC samples to be MSI positive. Significant correlations are observed with the overall MSI positive sample and MSI status of D3S1067 and D3S1561 (Fisher's exact test, $\mathrm{P}<0.0001$ and $\mathrm{P}=0.0094$ respectively, Table V). Our data also showed that MSI of D3S1067 was significantly correlated with $\mathrm{LOH}$ positive status of the 34 markers (Fisher's exact test, $\mathrm{P}=0.0348$, Table IV).

LOH analysis with 9 microsatellite markers in the 30 pairs of esophagus biopsy samples and their matched blood. Thirty esophagus biopsy samples, 28 with $\mathrm{BCH}$ and 2 with DYS 
Table II. LOH/MSI frequencies of the microsatellite markers.

\begin{tabular}{|c|c|c|c|c|c|}
\hline $\begin{array}{l}\text { Marker } \\
\text { code }\end{array}$ & Name & $\begin{array}{c}\text { Cytogenetic } \\
\text { location }\end{array}$ & Related gene(s) & $\begin{array}{c}\mathrm{LOH} / \mathrm{IF} \% \\
(\mathrm{LOH} / \mathrm{IF})\end{array}$ & MSI \% \\
\hline 54 & Bat 26 & $2 \mathrm{p} 16-2 \mathrm{p} 16$ & $h M S H 2$ intron 5 & $0 \quad(0 / 4)$ & $41(14)$ \\
\hline 57 & D2S123 & 2p16-2p16 & & $25(5 / 21)$ & 9 (3) \\
\hline 3 & D3S1067 & $3 p 21.1-3 p 14.3$ & & $55(12 / 22)$ & 21 \\
\hline 51 & D3S1561 & $3 \mathrm{p} 21$ & & $45 \quad(9 / 20)$ & 9 (3) \\
\hline 52 & D3S1611 & $3 \mathrm{p} 21$ & $h M L H 1$ intron & $39(7 / 18)$ & 21 \\
\hline 4 & D3S1038 & $3 p 26.1-3 p 25.2$ & & $36(8 / 22)$ & $18 \quad(4)$ \\
\hline 1 & FABP2 & $4 q 28-4 q 31$ & $F A B P 2$ & $40 \quad(8 / 20)$ & $15 \quad(5)$ \\
\hline 23 & D4S1613 & 4pter-4qter & & $50 \quad(9 / 18)$ & $6(2)$ \\
\hline 32 & D5S82 & $5 q 14-5 q 21$ & $\sim A P C$ & $23(5 / 22)$ & 12 (4) \\
\hline 31 & D5S299 & $5 q 15-5 q 22$ & $\sim A P C$ & $27(6 / 22)$ & $3(1)$ \\
\hline 49 & D6S1260 & $6 \mathrm{p} 21.3$ & $\sim V E G F$ & $29(7 / 24)$ & $9 \quad(3)$ \\
\hline 6 & D6S265 & $6 \mathrm{p} 22.3-6 \mathrm{p} 21.3$ & & $27(6 / 22)$ & $6 \quad(2)$ \\
\hline 7 & D6S105 & $6 \mathrm{p} 21.33-6 \mathrm{p} 22.1$ & & $30 \quad(8 / 26)$ & $0 \quad(0)$ \\
\hline 10 & D8S262 & $8 p 23-8 p 23$ & & $35(8 / 23)$ & $15(5)$ \\
\hline 11 & D8S273 & 8pter-8qter & & $12(3 / 25)$ & $6 \quad(2)$ \\
\hline 12 & D8S257 & $8 q 13-8 q 22.2$ & & $0 \quad(0 / 18)$ & $6(2)$ \\
\hline 13 & D8S167 & $8 \mathrm{q} 22.2-8 \mathrm{q} 22.2$ & & $21 \quad(5 / 24)$ & 12 (4) \\
\hline 45 & D8S85 & $8 \mathrm{q} 23.3-8 \mathrm{q} 23.3$ & EXT1 & $6(1 / 17)$ & 21 \\
\hline 15 & D9S171 & 9 p21-9p21 & & $60(6 / 10)$ & $0 \quad(0)$ \\
\hline 50 & D9S942 & $9 \mathrm{p} 21-9 \mathrm{p} 21$ & $\sim p 14, p 15, p 16$ & $23(5 / 22)$ & $32(11)$ \\
\hline 14 & D9S736 & 9 p22-9p22 & & $20 \quad(2 / 10)$ & $3(1)$ \\
\hline 38 & WT1 & $11 \mathrm{p} 13$ & $3^{\prime}$ of $W T 1$ untranslated & $31(4 / 13)$ & 12 (4) \\
\hline 16 & D11S873 & $11 q 14.3-11 q 21$ & & $29(8 / 28)$ & 3 (1) \\
\hline 37 & $\mathrm{RB} 1$ & $13 q 14.3-13 q 14.3$ & $R b$ intron 20 & $56(9 / 16)$ & $0 \quad(0)$ \\
\hline 27 & D13S170 & $13 q 31-13 q 31$ & & $38(10 / 26)$ & $15 \quad(5)$ \\
\hline 20 & D14S81 & $14 q 31-14 q 32$ & & $22(4 / 18)$ & $9 \quad(3)$ \\
\hline 21 & D14S51 & $14 q 32.1-14 q 32.2$ & & $19(4 / 21)$ & $9 \quad(3)$ \\
\hline 58 & $\mathrm{D} 17 \mathrm{~S} 250$ & $17 q 11.2-17 q 12$ & & $18(3 / 17)$ & $15(5)$ \\
\hline 22 & IMG412 & $17 \mathrm{p} 12-17 \mathrm{p} 11$ & & $38 \quad(8 / 21)$ & 21 \\
\hline 33 & p53-1 & 17p13.1-17p13.1 & p53 locus & $35(7 / 20)$ & $29(10)$ \\
\hline 34 & p53-2 & $17 \mathrm{p} 13.1-17 \mathrm{p} 13.1$ & p53 intron 1 & $50 \quad(4 / 8)$ & $12(4 / 33)$ \\
\hline 41 & NF1 & $17 q 11.2-17 q 11.2$ & NF1 intron 38 & $30 \quad(6 / 20)$ & $15 \quad(5)$ \\
\hline 40 & NM23-H1 & $17 \mathrm{q} 21.3-17 \mathrm{q} 21.3$ & $N M 23-H 1(\& B R C A 1)$ & $67(6 / 9)$ & $9(3)$ \\
\hline 43 & D18S363 & 18pter-18qter & DPC4 & $16(5 / 31)$ & 3 (1) \\
\hline 42 & D18S46 & $18 \mathrm{q} 12.1$ & $D P C 4$ & $32(7 / 22)$ & $3(1)$ \\
\hline 35 & DCC-1 & $18 \mathrm{q} 21.1-18 \mathrm{q} 21.1$ & DCC intron & $25(5 / 20)$ & 9 (3) \\
\hline 36 & DCC-2 & $18 \mathrm{q} 21.1-18 \mathrm{q} 21.1$ & DCC intron & $28 \quad(5 / 18)$ & $15(5)$ \\
\hline 48 & INF & $19 q 13.2$ & $\sim T G F-b e t a$ & $33(1 / 3)$ & $3\left(1 / 33^{a}\right)$ \\
\hline
\end{tabular}

IF, informative case. ${ }^{\text {aS }}$ ample number is 34 unless otherwise indicated. 
Table III. Summary of LOH/MSI data on different samples.

\begin{tabular}{|c|c|c|c|c|c|c|c|c|}
\hline Sample & $\begin{array}{c}\text { Differentiation } \\
\text { status of SCC }\end{array}$ & $\mathrm{LOH} \%$ & $\mathrm{D}$ & MSI \% & D3S1067 & D3S1561 & D3S1611 & Bat26 \\
\hline 1 & Poorly & $19(4 / 21)$ & $1 / 21$ & 3 (1) & $\mathrm{LOH}$ & $\mathrm{LOH}$ & $\mathrm{NI}$ & MSI \\
\hline 2 & Poorly & $32(7 / 22)$ & $2 / 22$ & $0 \quad(0)$ & $\mathrm{LOH}$ & $\mathrm{LOH}$ & NI & NI \\
\hline 3 & Well & $16(3 / 19)$ & $0 / 19$ & $0 \quad(0)$ & $\mathrm{LOH}$ & $\mathrm{N}$ & NI & MSI \\
\hline 4 & Mod. & $55(11 / 20)$ & $2 / 20$ & $0 \quad(0)$ & $\mathrm{D}$ & $\mathrm{LOH}$ & NI & MSI \\
\hline 5 & Well & $16(3 / 19)$ & $2 / 19$ & $0 \quad(0)$ & $\mathrm{D}$ & $\mathrm{N}$ & $\mathrm{LOH}$ & MSI \\
\hline 6 & Well & $41 \quad(9 / 22)$ & $1 / 22$ & 9 (3) & $\mathrm{LOH}$ & $\mathrm{LOH}$ & MSI & NI \\
\hline 7 & Poorly & $14(3 / 21)$ & $3 / 21$ & $0 \quad(0)$ & $\mathrm{LOH}$ & $\mathrm{N}$ & MSI & NI \\
\hline 8 & Well & $21 \quad(4 / 19)$ & $4 / 19$ & 9 (3) & NI & $\mathrm{N}$ & $\mathrm{N}$ & NI \\
\hline 9 & Well & $61(11 / 18)$ & $0 / 18$ & 3 (1) & NI & NI & $\mathrm{LOH}$ & NI \\
\hline 10 & Poorly & $18(4 / 22)$ & $5 / 22$ & $6 \quad(2)$ & $\mathrm{LOH}$ & NI & $\mathrm{N}$ & NI \\
\hline 11 & Poorly & $30 \quad(6 / 20)$ & $5 / 20$ & 3 (1) & $\mathrm{N}$ & $\mathrm{LOH}$ & $\mathrm{D}$ & NI \\
\hline 12 & Well & $46(11 / 24)$ & $3 / 24$ & $0 \quad(0)$ & $\mathrm{LOH}$ & NI & NI & NI \\
\hline 13 & Mod. & $43(9 / 21)$ & $2 / 21$ & 9 (3) & $\mathrm{LOH}$ & $\mathrm{LOH}$ & $\mathrm{LOH}$ & NI \\
\hline 14 & Poorly & $52(11 / 21)$ & $3 / 21$ & 9 (3) & NI & NI & $\mathrm{LOH}$ & NI \\
\hline 15 & Well & $40 \quad(6 / 15)$ & $0 / 15$ & 24 & MSI & $\mathrm{N}$ & $\mathrm{LOH}$ & MSI \\
\hline 16 & Mod. & $38 \quad(8 / 21)$ & $1 / 21$ & 18 (6) & MSI & $\mathrm{LOH}$ & $\mathrm{LOH}$ & MSI \\
\hline 17 & Poorly & $25(6 / 24)$ & $5 / 24$ & $0 \quad(0)$ & $\mathrm{LOH}$ & NI & NI & $\mathrm{N}$ \\
\hline 18 & Well & $14(3 / 22)$ & $3 / 22$ & $6 \quad(2)$ & $\mathrm{D}$ & NI & $\mathrm{D}$ & $\mathrm{N}$ \\
\hline 19 & Well & $0 \quad(0 / 23)$ & $0 / 23$ & $6 \quad(2)$ & $\mathrm{N}$ & NI & $\mathrm{N}$ & MSI \\
\hline 20 & Poorly & $0 \quad(0 / 20)$ & $0 / 20$ & 12 (4) & $\mathrm{N}$ & NI & $\mathrm{N}$ & $\mathrm{N}$ \\
\hline 21 & Well & $12(2 / 17)$ & $1 / 17$ & $24 \quad(8)$ & NI & NI & NI & $\mathrm{N}$ \\
\hline 22 & Well & $11 \quad(2 / 18)$ & $0 / 18$ & 18 (6) & MSI & $\mathrm{D}$ & $\mathrm{N}$ & NI \\
\hline 23 & Well & $21 \quad(4 / 19)$ & $1 / 19$ & 9 (3) & $\mathrm{LOH}$ & $\mathrm{N}$ & $\mathrm{D}$ & NI \\
\hline 24 & Well & $25 \quad(5 / 20)$ & $1 / 20$ & 3 (1) & $\mathrm{N}$ & $\mathrm{N}$ & MSI & NI \\
\hline 25 & Well & $47 \quad(7 / 15)$ & $2 / 15$ & 18 (6) & MSI & MSI & MSI & NI \\
\hline 26 & Well & $58 \quad(7 / 12)$ & $0 / 12$ & $41(14)$ & MSI & MSI & $\mathrm{N}$ & NI \\
\hline 27 & Well & $75(15 / 20 / 33)$ & $0 / 20 / 33$ & $9\left(3 / 33^{a}\right)$ & NI & $\mathrm{LOH}$ & MSI & NI \\
\hline 28 & Well & $40 \quad(4 / 10)$ & $0 / 10$ & $53(18)$ & MSI & MSI & MSI & MSI \\
\hline 29 & Well & $6 \quad(1 / 17)$ & $1 / 17$ & 3 (1) & $\mathrm{N}$ & $\mathrm{D}$ & $\mathrm{N}$ & MSI \\
\hline 30 & Poorly & $32(8 / 25)$ & $2 / 25$ & 3 (1) & $\mathrm{LOH}$ & NI & NI & MSI \\
\hline 31 & Well & $25(4 / 16)$ & $0 / 16$ & 12 (4) & $\mathrm{LOH}$ & $\mathrm{LOH}$ & MSI & MSI \\
\hline 32 & Poorly & $43 \quad(3 / 7)$ & $0 / 7$ & $32(11)$ & MSI & NI & $\mathrm{N}$ & MSI \\
\hline 33 & Mod. & $13(3 / 23)$ & $4 / 23$ & 3 (1) & $\mathrm{N}$ & $\mathrm{D}$ & NI & MSI \\
\hline 34 & Well & $25(6 / 24)$ & $4 / 24$ & 3 (1) & $\mathrm{N}$ & $\mathrm{N}$ & $\mathrm{LOH}$ & MSI \\
\hline
\end{tabular}

N, normal case; NI, non-informative case; LOH, case with loss of heterzygosity; MSI, case showed microsatellite instability; D, case showed 'decreased allelic ratio'. 'Sample number is 33 instead of 34.

were used for LOH study. Nine markers with high LOH ratio in ESCC samples were selected from 38 markers described above. The LOH results were summarized in Table VI. Informative cases ranged from $9(33 \%)$ to $23(77 \%)$ out of 30 cases. LOH was detected in 4 markers in 7 biopsy samples (Table VI). Two biopsy samples showed two LOH and 5 biopsy samples showed one $\mathrm{LOH}$ each. The $\mathrm{LOH}$ rates with two markers D9S942 and D9S171, both within locus 9p21, were 11 and $33 \%$, respectively. We also observed LOH using p53-1 (13.6\%) and RB1 (9.1\%) microsatellite markers.

\section{Discussion}

In this study, we analyzed chromosomal and microsatellite instability in both ESCC and biospy samples on the background that aberrations in the p53 and $\mathrm{Rb}$ tumor suppressor 
Table IV. Correlation between LOH and MSI status of $h M L H 1$ locus and $\mathrm{LOH}$ of the other 34 markers.

\begin{tabular}{lccccc}
\hline & \multicolumn{2}{c}{ hMLH1 locus $^{\mathrm{a}}$} & & \multicolumn{2}{c}{ D3S1067b } \\
\cline { 5 - 6 } & LOH & Non-LOH & & MSI & Non-MSI \\
\hline LOH status & & & & \\
(34 markers) & & & & \\
$\geq 25 \%$ & 6 & 10 & & 15 & 3 \\
$<25 \%$ & 1 & 17 & & 2 & 10 \\
\hline
\end{tabular}

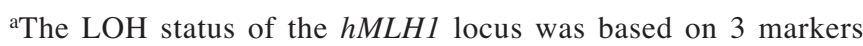
with priority sequence of D3S1611, D3S1561, and D3S1067. Its correlation with the LOH of the other 34 markers was analyzed by Fisher's exact test, $\mathrm{P}=0.0005$. ${ }^{\mathrm{b}}$ The correlation between D3S1067 MSI status and the LOH status of the other 34 markers was analyzed by Fisher's exact test, $\mathrm{P}=0.0348$.

Table V. Correlation of MSI status between $h M L H 1$ locus and the other 34 markers.

\begin{tabular}{lccccc}
\hline & \multicolumn{2}{c}{ D3S1067 } & & \multicolumn{2}{c}{ D3S1561 ${ }^{\mathrm{b}}$} \\
\cline { 2 - 3 } \cline { 5 - 6 } & MSI & Non-MSI & & MSI & Non-MS \\
\hline MSI status & & & & \\
(34 markers) & & & & \\
$\geq 18 \%$ & 0 & 1 & & 3 & 5 \\
$<18 \%$ & 0 & 26 & & 0 & 26
\end{tabular}

aThe correlation of MSI status between D3S1067 and the other 34 markers was analyzed by Fisher's exact test, $\mathrm{P}<0.0001$. ${ }^{\mathrm{b}}$ The correlation of MSI status between D3S1561 and the other 34 markers was analyzed by Fisher's exact test, $\mathrm{P}=0.0094$.

pathways, including epigenetic alterations in CDK inhibitors p14 ${ }^{A R F}$, p1 $15^{I N K 4 b}$, and p16 ${ }^{I N K 4 a}$ genes, are involved in the development of ESCC. We selected markers of different loci to monitor the overall chromosomal and microsatellite instability in these ESCC samples. We found that 38 out of our 58 selected microsatellite markers are suitable to monitor both chromosomal and genetic instability in these ESCC samples. These 38 microsatellite markers are on chromosomal arms 2p,
$3 \mathrm{p}, 4 \mathrm{q}, 5 \mathrm{q}, 6 \mathrm{p}, 8 \mathrm{p}, 8 \mathrm{q}, 9 \mathrm{q}, 11 \mathrm{p}, 11 \mathrm{q}, 13 \mathrm{q}, 14 \mathrm{q}, 17 \mathrm{p}, 17 \mathrm{q}$ $18 \mathrm{q}$, and 19q. Since we considered all the cases with MSI as non-informative in the LOH study, the heterozygosity determined was generally lower than reported in the GeneBank (National Center for Biotechnology Information). It was suggested that $\mathrm{LOH}$ with less than $22 \%$ incidence for a marker may be regarded as a background or non-specific event (28-30). We use $25 \%$ incidence as a cut-off point for $\mathrm{LOH}$, and 20 of the $34 \mathrm{ESCC}$ samples were $\mathrm{LOH}$ positive with $\mathrm{LOH}$ in over $25 \%$ of the markers. On average, $30.2 \%$ of informative markers displayed $\mathrm{LOH}$ in each sample. Therefore, our results showed that $\mathrm{LOH}$ is a frequent event in ESCC.

MSI is reported as a frequent event in esophageal adenocarcinoma, but not in $\operatorname{ESCC}(31,32)$. In this study, three ESCC samples showed MSI in more than $30 \%$ of the 38 markers, one of which showed MSI in $58 \%$ of the markers. The results suggest that MSI could be an important event in the development of a subset of ESCC. A large variation (from 0 to $67 \%$ ) of MSI frequency was observed among the 38 markers. This result suggests MSI is not accumulated uniformly through the genome, and certain loci are more susceptible to genetic alterations.

One of the most frequent LOH loci observed was D9S171 (9p21), where $p 15^{\text {INK4b }}$ and $\mathrm{p} 16^{\mathrm{INK} 4 \mathrm{a}}$ reside. With D9S171, LOH was previously reported to be $82 \%(14 / 17)$ in ESCC (32). In this study, using the same microsatellite marker D9S171, LOH was observed in 6 of the 10 informative cases. Interestingly, within the same 9p21 loci, marker D9S942 only showed $\mathrm{LOH}$ in $23 \%$ of the 22 informative cases. However, $32 \%$ of the 34 samples displayed MSI. This results suggest that loci 9 p21 is susceptible to both chromosomal and microsatellite instability. In our previous study (9), we found frequent genetic alteration events within loci 9p21. LOH at D9S171 was found to be associated with frequent homozygous deletion at $p 15^{I N K 4 b}$ but not with that at $p 16^{I N K 4 a}$. Furthermore, the incidence of D9S942 LOH was higher in samples without p15 INK4b deletion. In ESCC, both our current results and previous data may indicate that $9 \mathrm{p} 21$ is more susceptible to genetic alterations than other loci.

With the microsatellite marker located in $R b$ intron 20 , $\mathrm{LOH}$ was found to be $56 \%(9 / 16)$, which is in close agreement with the two previous reports on the $\mathrm{LOH}$ of intron 17 in the $\operatorname{ESCC}(7,30)$. Furthermore, in our previous study, LOH at the $R b$ locus was $55 \%$, where the sample was considered to be $\mathrm{LOH}$ positive if $\mathrm{LOH}$ was detected at any one of 4 markers (7). No MSI was detected in any of the samples, agreeing with the inverse relationship between LOH and MSI observed in other cancers (33). These data may suggest chromosomal

Table VI. Summary of LOH status in 30 biopsy samples based on 9 selected markers.

\begin{tabular}{lccccccrrr}
\hline Marker & D9S942 & D3S1561 & RB1 & p53-2 & NF1 & D9S171 & D8S167 & D3S1611 & p53-1 \\
\hline Informative & 18 & 16 & 11 & 9 & 23 & 9 & 20 & 12 \\
LOH & 2 & 0 & 1 & 0 & 0 & 3 & 0 & 0 \\
\hline
\end{tabular}


instability is a frequent event within chromosome 13 , especially between 13q14.3-13q14.3. In contract, chromosomal microenvironment between 13q14.3-13q14.3 may not allow the occurrence of microsatellite instability.

$\mathrm{LOH}$ at or near the $p 53$ gene locus has been shown to occur in a variety of human tumors $(29,34)$. With p53-2 (located in p53 intron 1), 4 of the 8 informative cases showed $\mathrm{LOH}$, which is close to the ratio previously reported for ESCC (35). With p53-1 (located in 17p13.1), we observed LOH in $35 \%(7 / 20)$ of the informative cases. This is comparable to our previous study with another series of 30 samples (unpublished data). $\mathrm{LOH}$ at 17 p13 loci was reported to be infrequent in esophageal dysplasia (2/8) and increased in ESCC (7/16) (35). Additional studies with more samples are needed to reach a firm conclusion on the timing of this molecular alteration. No correlation between LOH in the p53 locus and p53 mutations (data not shown) was found in our study. Interestingly, significant correlation between p53 mutation and $\mathrm{LOH}$ in $h M L H 1$ locus was observed. Our data might suggest loss or decreased function of the $h M L H 1$ gene in mismatch repair could allow a high mutation rate for $p 53$.

Statistically significant correlations were found between LOH of $h M L H 1$ locus and the general LOH status of the samples, and between MSI in D3S1067/D3S1561 and the general MSI status in the sample. However, no correlation was found between $\mathrm{LOH}$ at microsatellite markers linked to the hMSH2 and MSI in hMLH1, which is different from previous reports on other cancers (36). Mutations of the mismatch repair genes were reported to play important roles in carcinogenesis (37-39), and microsatellite markers within both the hMLHI and $h M S H 2$ genes have been used as an indicator of the MSI status in cancer (27). However, our data showed that MSI of two markers in the introns of $h M L H 1$ and $h M S H 2$, were not correlated with the general MSI status of the samples in this study (the Fisher's exact test, $\mathrm{P}>0.6$ for both). On the other hand, two markers from the $h M L H 1$ gene locus (D3S1067, D3S1561) sensitively reflected the MSI status. Currently, it is not clear whether and how the function of $h M L H 1$ is affected by these two distance markers within the same locus.

In the present study, we found the MSI status of the ESCC samples was independent of their differentiation status. Our findings agree with the result of adenocarcinomas of the stomach (40). We found that genetic alterations with other tumor suppressor genes or oncogenes such as $A P C$ on chromosome 5, WT1 on chromosome 11, DPC4 and DCC on chromosome 18 were infrequent in ESCC, even though changes in these genes are prominent in other types of cancer $(18-23,34)$.

Based on our results, we suggest that the following nine markers are useful for genetic alteration analysis in ESCC and in precancerous lesions: $h M L H 1$ linked markers (D3S1611, and D3S1561), p53 linked markers (p53-1 and p53-2), p14 ${ }^{A R F}$, p15 INK4b,$p 16^{\text {INK4a }}$ linked markers (D9S171 and D9S942), RB1, FABP2, and NF1. All of these markers showed a high incidence of LOH, MSI, or both in ESCC. We performed a preliminary study on these nine microsatellite markers in 30 pairs of biopsy samples with $\mathrm{BCH}$ and DYS. Our data showed that among the nine microsatellite markers spanning chromosomes 3, 4, 9, 13 and 17, there was frequent occurrence of chromosomal instability in chromosomes 9 and 17 related to 9 p21 and p53 gene regions, respectively. LOH was detected in 5 out of 27 informative biopsy cases within the $9 \mathrm{p} 21$ region, and 3 out of 22 within the $p 53$ gene region. This chromosomal instability within $9 \mathrm{p} 21$ region and $p 53$ gene regions confirm our previous finding that $\mathrm{p} 53$ and $\mathrm{Rb}$ tumor suppressor pathways are important for the development of ESCC (7).

In concusion, both chromosomal and microsatellite instability in chromosomes $3,4,9,13$, and 17 occur frequently in ESCC. Chromosomal instability in chromosomes 9 and 17 are an early event observed in biopsy samples. Both the p53 and $\mathrm{Rb}$ tumor suppressor pathways might be important for the initiation and progression of ESCC.

\section{Acknowledgements}

This study was supported by NIH Grant CA65871, facilities from the NIEHS Center Grant ES05022 and the Cancer Center Support Grant CA72720, and the China National Natural Science Foundation Grant 39770296.

\section{References}

1. Parkin DM, Bray F, Ferlay J and Pisani P: Global cancer statistics, 2002. CA Cancer J Clin 55: 74-108, 2005.

2. Morgan G: Epidemiology of oesophageal cancer. J R Soc Med 88: 119, 1995 .

3. Yang CS: Nitrosamines and other etiological factors in the esophageal cancer in Northern China. In: Nitrosamines in Human Cancer. Magee PN (ed.) Cold Spring Harbor Laboratory, New York, 1982.

4. Yang CS: Research on esophageal cancer in China: a review. Cancer Res 40: 2633-2644, 1980.

5. Gao H, Wang LD, Zhou Q, Hong JY, Huang TY and Yang CS: p53 tumor suppressor gene mutation in early esophageal precancerous lesions and carcinoma among high-risk populations in Henan, China. Cancer Res 54: 4342-4346, 1994.

6. Wang LD, Hong JY, Qiu SL, Gao H and Yang CS: Accumulation of p53 protein in human esophageal precancerous lesions: a possible early biomarker for carcinogenesis. Cancer Res 53: 1783-1787, 1993.

7. Xing EP, Yang GY, Wang LD, Shi ST and Yang CS: Loss of heterozygosity of the $\mathrm{Rb}$ gene correlates with $\mathrm{pRb}$ protein expression and associates with p53 alteration in human esophageal cancer. Clin Cancer Res 5: 1231-1240, 1999.

8. Xing EP, Nie Y, Song Y, Yang GY, Cai YC, Wang LD and Yang CS: Mechanisms of inactivation of p14ARF, p15INK4b, and p16INK4a genes in human esophageal squamous cell carcinoma. Clin Cancer Res 5: 2704-2713, 1999.

9. Xing EP, Nie Y, Wang LD, Yang GY and Yang CS: Aberrant methylation of p16INK4a and deletion of p15INK4b are frequent events in human esophageal cancer in Linxian, China. Carcinogenesis 20: 77-84, 1999.

10. Nie Y, Yang G-Y, Song Y, et al: DNA hypermethylation is a mechanisms for loss of expression of the HLA class I genes in human esophageal squamous cell carcinomas. Carcinogenesis 22: 1615-1623, 2001 .

11. Nie Y, Liao J, Zhao X, Song Y, Yang G-Y, Wang L-D and Yang CS: Detection of multiple gene hypermethylation in the development of esophageal squamous cell carcinoma. Carcinogenesis 23: 1713-1720, 2002.

12. Wang Y, Fang MZ, Liao J, et al: Hypermethylation associated inactivation of retinoic acid receptor beta (RARb) in human esophageal squamous cell carcinoma. Clin Cancer Res 9: 5257-5263, 2003.

13. Fang MZ, Jin Z, Liao J, Wang Y, Yang G-Y, Wang L-D and Yang CS: Promoter hypermethylation and inactivation of $\mathrm{O}^{6}-$ methylguanine-DNA methyltransferase in esophageal squamous cell carcinoma. Int J Oncol 26: 615-622, 2005.

14. Hu N, Flaig MJ, Su H, et al: Comprehensive characterization of annexin I alterations in esophageal sqamous cell carcinoma. Clin Cancer Res 10: 6013-6022, 2004.

15. Roth MJ, Hu N, Emmert-Buck MR, et al: Genetic progression and heterogeneity associated with the development of esophageal squamous cell carcinoma. Cancer Res 61: 4098-4104, 2001. 
16. Hu N, Wang C, Hu Y, et al: Genome-wide association study in esophageal cancer using GeneChip Mapping 10K Array. Cancer Res 65: 2542-2546, 2005.

17. Mao X, Hamoud, RA, Talbot IC and Baudis M: Allele-specific loss of heterozygosity in multiple colorectal adenomas: toward an integrated molecular cytogenetic map II. Cancer Genet Cytogenet 167: 1-14, 2006.

18. Black D, Soslow RA, Levine DA, et al: Clinicopathologic significance of defective DNA mismatch repair in endometrial carcinoma. J Clin Oncol 24: 1745-1753, 2006.

19. Soreide K, Janssen EA, Soiland H, Korner H and Baak JP Microsatellite instability in colorectal cancer. Br J Surg 93: 395-406, 2006.

20. Gaasenbeek M, Howarth K, Rowan AJ, et al: Combined arraycomparative genomic hybridization and single-nucleotide polymorphism-loss of heterozygosity analysis reveals complex changes and multiple forms of chromosomal instability in colorectal cancers. Cancer Res 66: 3471-3479, 2006.

21. Jeter JM, Kohlmann W and Gruber SB: Genetics of colorectal cancer. Oncology 20: 269-276, 2006.

22. Hamilton JP and Meltzer SJ: A review of the genomics of gastric cancer. Clin Gastroenterol Hepatol 4: 416-425, 2006.

23. Chang EY, Dorsey PB, Johnson N, et al: A prospective analysis of microsatellite instability as a molecular marker in colorectal cancer. Am J Surg 191: 646-651, 2006

24. Boland CR, Thibodeau SN, Hamilton SR, et al: A National Cancer Institute Workshop on microsatellite instability for cancer detection and familial predisposition: development of international criteria for the determination of microsatellite instability in colorectal cancer. Cancer Res 58: 5248-5257, 1998.

25. Zou TT, Lei J, Shi YQ, et al: FHIT gene alterations in esophageal cancer and ulcerative colitis (UC). Oncogene 15: 101-105, 1997.

26. Aoki T, Mori T, Du X, Nisihira T, Matsubara T and Nakamura Y: Allelotype study of esophageal carcinoma. Genes Chromosomes Cancer 10: 177-182, 1994

27. Dietmaier W, Wallinger S, Bocker T, Kullmann F, Fishel R and Ruschoff J: Diagnostic microsatellite instability: definition and correlation with mismatch repair protein expression. Cancer Res 57: 4749-4756, 1997
28. Wagata T, Ishizaki K, Imamura M, Shimada Y, Ikenaga $M$ and Tobe T: Deletion of $17 \mathrm{p}$ and amplification of the int- 2 gene in esophageal carcinomas. Cancer Res 51: 2113-2117, 1991.

29. Meltzer SJ, Yin J, Huang Y, et al: Reduction to homozygosity involving $\mathrm{p} 53$ in esophageal cancers demonstrated by the polymerase chain reaction. Proc Natl Acad Sci USA 88: 4976-4980, 1991.

30. Boynton RF, Huang Y, Blount PL, et al: Frequent loss of heterozygosity at the retinoblastoma locus in human esophageal cancers. Cancer Res 51: 5766-5769, 1991.

31. Meltzer SJ, Yin J, Manin B, et al: Microsatellite instability occurs frequently and in both diploid and aneuploid cell populations of Barrett's-associated esophageal adenocarcinomas. Cancer Res 54: 3379-3382, 1994

32. Tarmin L, Yin J, Zhou X, et al: Frequent loss of heterozygosity on chromosome 9 in adenocarcinoma and squamous cell carcinoma of the esophagus. Cancer Res 54: 6094-6096, 1994.

33. Lengauer C, Kinzler KW and Vogelstein B: Genetic instabilities in human cancers. Nature 396: 643-649, 1998.

34. Vogelstein B: Cancer. A deadly inheritance. Nature 348: 681-682, 1990

35. Mori T, Yanagisawa A, Kato Y, Miura K, Nishihira T, Mori S and Nakamura Y: Accumulation of genetic alterations during esophageal carcinogenesis. Hum Mol Genet 3: 1969-1971, 1994.

36. Macdonald GA, Greenson JK, Saito K, Cherian SP, Appelman HD and Boland CR: Microsatellite instability and loss of heterozygosity at DNA mismatch repair gene loci occurs during hepatic carcinogenesis. Hepatology 28: 90-97, 1998.

37. Bronner CE, Baker SM, Morrison PT, et al: Mutation in the DNA mismatch repair gene homologue hMLH1 is associated with hereditary non-polyposis colon cancer. Nature 368: 258-261, 1994.

38. Leach FS, Nicolaides NC, Papadopoulos N, et al: Mutations of a mutS homolog in hereditary nonpolyposis colorectal cancer. Cell 75: 1215-1225, 1993.

39. Papadopoulos N, Nicolaides NC, Wei YF, et al: Mutation of a mutL homolog in hereditary colon cancer. Science 263: 1625-1629, 1994.

40. Semba S, Yokozaki H, Yamamoto S, Yasui W and Tahara E: Microsatellite instability in precancerous lesions and adenocarcinomas of the stomach. Cancer 77: 1620-1627, 1996. 